\title{
Analysis of trastuzumab and chemotherapy in advanced breast cancer after the failure of at least one earlier combination: An observational study
}

\author{
Rupert Bartsch, Catharina Wenzel, Dagmar Hussian, Ursula Pluschnig, \\ Ursula Sevelda, Wolfgang Koestler, Gabriela Altorjai, Gottfried J Locker, \\ Robert Mader, Christoph C Zielinski and Guenther G Steger*
}

Address: Department of Internal Medicine I, Division of Oncology, Medical University of Vienna, Vienna, Austria

Email: Rupert Bartsch - rupert.bartsch@meduniwien.ac.at; Catharina Wenzel - catharina.wenzel@meduniwien.ac.at; Dagmar Hussian - dagmar.hussian@meduniwien.ac.at; Ursula Pluschnig - ursula.pluschnig@meduniwien.ac.at; Ursula Sevelda - ursula.sevelda@meduniwien.ac.at; Wolfgang Koestler - wolfgang.koestler@meduniwien.ac.at; Gabriela Altorjai - gabriela.altorjai@meduniwien.ac.at; Gottfried J Locker - gottfried.locker@meduniwien.ac.at; Robert Mader - robert.mader@meduniwien.ac.at; Christoph C Zielinski - christoph.zielinski@meduniwien.ac.at; Guenther G Steger* - guenther.steger@meduniwien.ac.at

* Corresponding author

Published: 15 March 2006

BMC Cancer2006, 6:63 doi:10.1/86/147|-2407-6-63

This article is available from: http://www.biomedcentral.com/l47/-2407/6/63

(C) 2006Bartsch et al; licensee BioMed Central Ltd.

This is an Open Access article distributed under the terms of the Creative Commons Attribution License (http://creativecommons.org/licenses/by/2.0), which permits unrestricted use, distribution, and reproduction in any medium, provided the original work is properly cited.
Received: 05 October 2005

Accepted: 15 March 2006

\begin{abstract}
Background: Combining trastuzumab and chemotherapy is standard in her2/neu overexpressing advanced breast cancer. It is not established however, whether trastuzumab treatment should continue after the failure of one earlier combination. In this trial, we report our experience with continued treatment beyond disease progression.
\end{abstract}

Methods: Fifty-four patients, median age 46 years, range $25-73$ years, were included. We analysed for time to tumour progression (TTP) for first, second and beyond second line treatment, response rates and overall survival.

Results: Median time of observation was 24 months, range 7-5I. Response rates for first line treatment were $7.4 \%$ complete remission (CR), 35.2\% partial remissions (PR), $42.6 \%$ stable disease $>6$ months (SD) and $14.8 \%$ of patients experienced disease progression despite treatment (PD). Corresponding numbers for second line were $3.7 \% \mathrm{CR}, 22.2 \% \mathrm{PR}, 42.6 \% \mathrm{SD}$ and $31.5 \% \mathrm{PD}$; numbers for treatment beyond second line $\left(60\right.$ therapies, 33 pts $3^{\text {rd }}$ line, 18 pts $4^{\text {th }}$ line, 6 pts $5^{\text {th }}$ line, 2 pts $6^{\text {th }}$ line and I patient $7^{\text {th }}$ line) were I.7\% CR, 28.3\% PR, 28.3\% SD and $41.6 \%$ PD respectively. Median TTP was 6 months $(\mathrm{m})$ in the first line setting, and also $6 \mathrm{~m}$ for second line and beyond second line. An asymptomatic drop of left ventricular ejection fraction below $50 \%$ was observed in one patient. No case of symptomatic congestive heart failure was observed.

Conclusion: The data presented clearly strengthen evidence that patients do profit from continued trastuzumab treatment. The fact that TTP did not decrease significantly from first line to beyond second line treatment is especially noteworthy. Still, randomized trials are warranted. 


\section{Background}

Breast cancer remains the main cause of cancer morbidity and mortality in women in most countries all over the world $[1,2]$. While localised disease is potentially curable, even in stage I and II disease, $30 \%$ of patients can be expected to experience a relapse [3]. Especially at risk for cancer recurrence are patients of young age, nodal positive tumours and individuals with aggressive tumour phenotypes, defined as high or intermediate grade, endocrine receptor negative and/or her $2 /$ neu positive $[4,5]$. When metastatic disease develops, appropriate therapeutic strategies are necessary to lengthen the patient's survival while not further reducing her quality of life.

In her2/neu positive tumours, a combination of chemotherapy and trastuzumab has proven to produce superior response rates and a longer time to progression than chemotherapy alone [6-10]. Trastuzumab is a monoclonal humanized antibody targeting the epidermal growth factor receptor 2 (her2/neu), resulting in an antitumour activity whose exact mechanism of action is not yet fully understood. Antibody dependent cytotoxicity (ADCC) is part of this mechanism, but also the blocking of post-receptor pathways and the inhibition of homoand hetero-dimerization are thought to play a crucial role [11-13]. A benefit however can only be found in tumours with her2/neu 3+ over-expression in immunohistochemistry or in cells with her2/neu gene amplification, which is usually analysed by FISH (fluorescence in situ hybridisation) [14]. Paclitaxel plus trastuzumab was the first combination regimen established [15]. While in vitro studies were able to demonstrate an additive anti-tumour effect of this combination, other substances (vinorelbine, docetaxel, and cisplatin) showed a synergistic effect [16]. In vivo, it was possible to demonstrate, that vinorelbine plus trastuzumab regimens are not only superior to paclitaxel containing regimens in terms of toxicity [17], but also in terms of response and survival $[9,10,16,18]$. A recent study found docetaxel plus trastuzumab highly superior to docetaxel monotherapy as first line palliative treatment with little additional toxicity [19].

Today, a first line palliative combination of chemotherapy and trastuzumab can already be deemed standard. Still, it is not established whether or not patients do achieve a benefit from continuing trastuzumab treatment combined with a different chemotherapeutic agent after the failure of one earlier combination, as the way a resistance to trastuzumab develops is not yet understood entirely. Because of limited resources, also pharmacoeconomic aspects must be taken in account.

At our centre, patients were routinely treated with trastuzumab also in the second line and beyond second line setting. Individuals were observed prospectively, and we are reporting our experiences with trastuzumab treatment after the failure of at least one earlier trastuzumab containing therapy regimen.

\section{Methods}

All data were collected at the Department of Internal Medicine I, Division of Oncology at the Medical University of Vienna, Vienna, Austria. Treatment was performed in accordance with the ethical regulations of the Medical University of Vienna.

\section{Patients}

Fifty-four consecutive patients were included into to this trial after progressing on first line trastuzumab based treatment, and were followed prospectively. Prospective follow up of the first patient started in May 2002. The retrospective starting point of the study (i.e. the date the first patient received the first cycle of trastuzumab based $1^{\text {st }}$ line therapy) was June 2001. All patients were suffering from histological confirmed her2/neu (HERcepTest+++/ FISH positive) positive advanced breast cancer and were treated with at least two palliative lines of trastuzumab containing therapy regimens. For staging evaluations, CTscan of the chest and the abdomen, mammography, echocardiography, and gynaecologic examination were mandatory at baseline.

\section{Treatment plan and patient evaluation}

All treatment was administered in the outpatient setting. Patients received trastuzumab in a dose of $8 \mathrm{mg} / \mathrm{kg}$ body weight loading dose on the first day of treatment, followed by $6 \mathrm{mg} / \mathrm{kg}$ body weight every three weeks [20]. Reevaluation of patients' tumour status was performed with CT-scan of the chest and the abdomen with additional work up if indicated every three cycles of therapy. Echocardiography was repeated at irregular intervals, longest every 6 months. Complete response (CR) was defined as the disappearance of all measurable lesions for a minimum of eight weeks. Partial response (PR) was defined as $25 \%$ or more reduction in sum of products of the greatest diameters of measurable lesions, no increase of lesion size and no new lesions. Stable disease (SD) was defined as less than 25\% decrease and less than 25\% increase without the appearance of new lesions. Progressive disease (PD) was defined as greater than $25 \%$ increase in tumour size or the appearance of new lesions.

\section{Statistical analysis}

Time to progression (TTP) was defined as the interval from the first day of application of a new therapy line until tumour progression. Data was analysed as of August 2005. TTP was estimated using the Kaplan-Meier productlimit method [21]. To test the difference between TTP curves, the log-rank test was used. $p$ values less than 0.05 were considered to indicate statistical significance. Toxic- 
Table I: Patient characteristics

\begin{tabular}{|c|c|}
\hline Characteristics & Patients \\
\hline Entered & $\mathrm{n}=54$ \\
\hline Age median (years) (range) & 46 years (range $25-73$ y) \\
\hline $\begin{array}{l}\text { Estrogen receptor/progesterone } \\
\text { receptor positive }\end{array}$ & $23 / 15$ \\
\hline HERcepTest+++/FISH+ & $51 / 3$ \\
\hline primary metastatic disease & $12(22.2 \%)$ \\
\hline Metastatic sites median (range) & 3 (range I-7 sites) \\
\hline Lung & 22 \\
\hline Liver & 29 \\
\hline Bones & 30 \\
\hline Lymph nodes & 22 \\
\hline Soft tissue & 36 \\
\hline Skin & 11 \\
\hline Brain & II \\
\hline Others & 3 \\
\hline More than one metastatic site & $48(88.8 \%)$ \\
\hline Adjuvant chemotherapy & $31(57.4 \%)$ \\
\hline Adjuvant docetaxel & 13 \\
\hline Adjuvant anthracyclines & 19 \\
\hline Adjuvant endocrine therapy & $15(27.7 \%)$ \\
\hline Palliative endocrine therapy & $20(37 \%)$ \\
\hline Ist line combination $^{\text {st }}$ & $\mathrm{n}=54 \mathrm{pts}$ \\
\hline Vinorelbine & 35 \\
\hline Capecitabine & 2 \\
\hline Gemcitabine & 0 \\
\hline Docetaxel & 12 \\
\hline Platinum derivatives & 0 \\
\hline Others & 5 \\
\hline $2^{\text {nd }}$ line combination & $\mathrm{n}=54 \mathrm{pts}$ \\
\hline Vinorelbine & 15 \\
\hline Capecitabine & 11 \\
\hline Gemcitabine & 9 \\
\hline Docetaxel & 11 \\
\hline Platinum derivatives & 0 \\
\hline Others & 8 \\
\hline Beyond $2^{\text {nd }}$ line combination & $\mathrm{n}=60$ therapies \\
\hline Vinorelbine & 6 \\
\hline Capecitabine & 14 \\
\hline Gemcitabine & 14 \\
\hline Docetaxel & 4 \\
\hline Platinum derivatives & 11 \\
\hline Others & 11 \\
\hline
\end{tabular}

ity was evaluated according to the WHO criteria and was recorded per patient as the worst episode that occurred on a certain therapy. Echocardiography data were recorded, and development of left ventricular function during treatment was reported.

\section{Results}

\section{Patient characteristics}

Fifty-four patients (53 female/1 male) suffering from her2/neu positive metastatic breast cancer were included in this evaluation. Median age was 46 years, range 25-73 years. Table 1 lists the characteristics of all patients included. $89.8 \%$ had invasive ductal carcinoma and

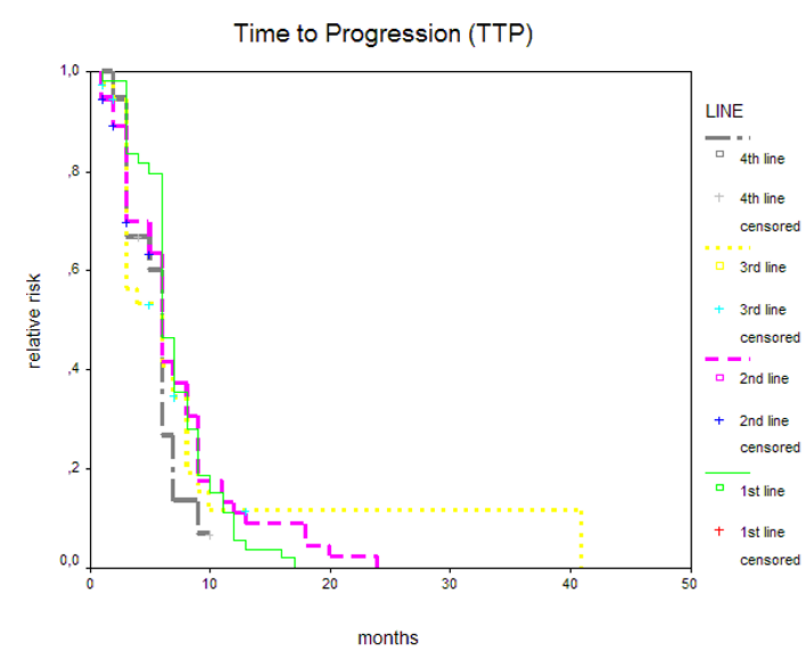

Figure I

Time to progression (months) for $\left.\right|^{\text {st }}, 2^{\text {nd }}, 3^{\text {rd }}$, and $4^{\text {th }}$ line trastuzumab based combination therapy.

$10.2 \%$ were suffering from invasive lobular carcinoma. Twenty-three patients had positive estrogens receptors and fifteen also a positive progesterone receptor. Thirtyone patients were treated with adjuvant chemotherapy, with nineteen patients receiving anthracyclin based regimens and thirteen taxane containing therapies. Adjuvant endocrine therapy was administered in 15 patients (14 patients received tamoxifen and one anastrozole). Twelve patients had metastases at the time of primary diagnosis. Median time to development of metastases in the other 42 patients was 23 months, range $2-210$ months. Six patients had only visceral metastases, ten metastases in the bones and/or the soft tissue, and the remaining 38 patients had metastases of both risk groups. Median number of metastatic sites was 3, range 1-7 sites. In 14 individuals, a trastuzumab containing combination was not the first palliative line of treatment. Those patients had received one earlier line of palliative therapy with aromatase inhibitors without trastuzumab.

Most common combination partners were: vinorelbine ( $\mathrm{n}$ $=55)$, docetaxel $(n=28)$, capecitabine $(n=28)$, gemcitabine $(\mathrm{n}=25)$, platinum derivatives $(\mathrm{n}=13)$, others $(\mathrm{n}=$ 28).

\section{Response and survival data}

All fifty-four patients are evaluable for response and toxicity. Median time of observation (all trastuzumab containing treatment lines) was 24 months, range $7-51$ months. Median time of observation in the first line setting was 6 months (range 1 - 17 months), and corresponding numbers were median 6 months (range 1 - 24 months) for second line, 5 months (range $1-41$ months) for third line, 
Table 2: Toxicities ( $n=54$ patients). (toxicities shown as worst episode per therapy)

\begin{tabular}{|c|c|c|c|c|}
\hline \multirow[t]{2}{*}{ Toxicity } & \multicolumn{4}{|c|}{ WHO grade } \\
\hline & 1 & II & III & IV \\
\hline Nausea/Vomiting & I (I.8\%) & $13(24.1 \%)$ & I (I.9\%) & - \\
\hline Neutropenia & - & $4(7.4 \%)$ & $14(25.9 \%)$ & $5(9.3 \%)$ \\
\hline Thrombocytopenia & - & $5(9.3 \%)$ & $2(3.7 \%)$ & - \\
\hline Anaemia & $18(33.3 \%)$ & $7(13 \%)$ & $6(11.1 \%)$ & - \\
\hline Diarrhoea & - & $4(7.4 \%)$ & - & - \\
\hline Stomatitis & - & $2(3.7 \%)$ & $2(3.7 \%)$ & - \\
\hline Polyneuropathia & I (I.8\%) & $2(3.7 \%)$ & - & - \\
\hline Hand-Foot-Syndrom & $3(5.6 \%)$ & $10(18.1 \%)$ & $3(5.6 \%)$ & - \\
\hline
\end{tabular}

5.5 months (range 3 - 10 months) for fourth line, 4.5 months (range 1 - 12) for fifth line, 7 months (range 6 8 months) for sixth line, and 3 months for seventh line respectively. Response rates for first line combination treatment were $7.4 \%$ complete remission (CR), 35.2\% partial remissions (PR), 42.6\% stable disease (SD) and $14.8 \%$ of patients experienced disease progression despite treatment (PD). Corresponding numbers for second line were $3.7 \%$ CR, 22.2\% PR, $42.6 \%$ SD and 31.5\% PD; numbers for treatment beyond second line $(60$ therapies, 33 pts $3^{\text {rd }}$ line, 18 pts $4^{\text {th }}$ line, 6 pts $5^{\text {th }}$ line, 2 pts $6^{\text {th }}$ line and 1 patient $7^{\text {th }}$ line) were $1.7 \% \mathrm{CR}, 28.3 \% \mathrm{PR}, 28.3 \% \mathrm{SD}$ and $41.4 \%$ PD respectively. Two patients showed response to a sixth line treatment. Forty-six patients (85.2\%) experienced a clinical benefit $(C R+P R+S D \geq 6$ months) from first line treatment, $68.5 \%$ from second line, and 35/60 treatments (58.3\%) beyond second line. TTP was 6 months (m) (range 1-17 m, 95\% CI 5.40 $6.60)$ in the first line setting, $6 \mathrm{~m}(1-24 \mathrm{~m}, 95 \%$ CI 5.36 $6.64)$ in the second line and also $6 \mathrm{~m} \mathrm{(1-41} \mathrm{m,95 \%} \mathrm{CI}$ $5.32-6.68$ ) beyond second line. Log rank test revealed no significant difference between the groups. TTP for $3^{\text {rd }}$ line was $6 \mathrm{~m}$ (range $1-41 \mathrm{~m}, 95 \% \mathrm{CI} 2.79-9.21$ ), and $4^{\text {th }}$ line $6 \mathrm{~m}$ (range 2-10+ m, 95\% CI 5.34-6.66) respectively (Figure 1). TTP for $5^{\text {th }}$ line treatment was 6 months (range 2$12 \mathrm{~m}, 95 \%$ CI 2.74-9.26) and actual progression time was median $6 \mathrm{~m}$. No Kaplan-Maier estimations are available for 6th and 7th line treatment, as only one patient has yet progressed on $6^{\text {th }}$ line therapy (after 8 months), and the only patient receiving a 7 th line treatment progressed after 3 months. Median survival was not reached after 24 months. Two patients, who experienced disease progression on first line treatment, responded with PR to second line therapy. Of three patients with PD in second line (from a total of sixteen), one showed a PR and four SD during later lines of therapy. Two patients were lost to follow up at the time of analysis and were therefore not evaluable for overall survival.

\section{Toxicity}

All side effects are shown in Table 2. Trastuzumab based therapy was well tolerated and we observed no case of treatment related death. There was also no case of symptomatic congestive heart failure. In one patient, left ventricular ejection fraction dropped below 50\% without symptoms, therefore necessitating a discontinuation of therapy. Still, this decrease was fully reversible, and output rate normalised over the next 12 months.

Other toxicities observed were caused by the chemotherapy agents used as combination partners. A WHO grade IV neutropenia was observed in 5 patients, with no other grade IV toxicity reported. WHO grade III toxicities included stomatitis ( 2 patients), nausea (1 patient), neutropenia (14 patients), thrombocytopenia (2 patients), hand-foot-syndrome (3 patients) and anaemia (6 patients).

\section{Discussion}

While there is some evidence from different other, mostly retrospective, trials reporting a benefit from continued trastuzumab treatment beyond disease progression with a changed chemotherapy regimen only [22-24], a discontinuation after disease progression is still standard of care. Though the here presented study is limited by the relatively small number of patients included, we are clearly able to strengthen existing evidence that there is a benefit for at least some patients.

The reported decline in response rates from $42.6 \%$ in first line treatment to $30 \%$ in beyond second line compares to the expected drop of response rates with every further line of chemotherapy or endocrine therapy in palliative treatment. Stable disease and objective response combined, clinical benefit rates were $85.2 \%$ in first line, $68.5 \%$ in second line and $58.3 \%$ in beyond second line. As some other groups, we believe this to be the more significant parameter in judging the efficacy of palliative treatment, as a stabilisation of the disease without excessive toxicity often appears more important than objective remission $[25,26]$. The high clinical benefit rate of nearly $60 \%$ even beyond second line must be seen as a clear sign of a benefit that most patients gain from treatment continuation. It is also obvious from our here presented data that this benefit is 
not paid for by excess toxicity, as apart from a possible drop in cardiac output rate, no other major toxicity linked to trastuzumab was observed. This was especially important to us, as some patients included in this trial were treated with trastuzumab for more than 3 years. Notably, we did not find a case of symptomatic congestive heart failure. All other toxicities were well within the range expected from the different chemotherapy regimens. Still, in one patient, treatment had to be discontinued because of a drop in ejection fraction below $50 \%$. So while trastuzumab based regimens are well tolerated also in medium and long term treatment, a monitoring of cardiac function remains essential. Echocardiography only in the case of symptoms appears not to be sufficient.

Of special interest is the fact, that we did not find a statistical significant difference in TTP between first line, second line and beyond second line trastuzumab based combinations. Although we rather expected to observe a shortening of time to disease progression with every further line of therapy, as this is the usual development in the metastatic setting, we believe this to be another sign of a potential benefit from continued combination treatment. TTP data from the different treatment lines (median 6 months in $1^{\text {st }}$ line, $2^{\text {nd }}$ line and beyond $2^{\text {nd }}$ line) compare favourably to the data reported in the pivotal trastuzumab trial with median 6.9 months in combination with paclitaxel as first line therapy [27]. As median overall survival was not yet reached, we believe that our survival data will be well beyond the median 25.4 months presented in the pivotal trial. These results are intriguing and somewhat unexpected, but still the necessity for larger, especially randomised, trials remains.

A big problem lies in the fact, that the mechanism of resistance to trastuzumab is not yet fully understood. If tumour cells are able to switch the main growth pathway from the her2/neu receptor to the EGFR or other signal transduction pathways, a continued treatment would not necessarily lead to a benefit. On the other hand, if no complete resistance develops, a discontinuation of trastuzumab might cause a massive overshoot in tumour growth, in which case only combination partners should be switched $[28,29]$. With limited resources available, also economic aspects must be taken on account.

\section{Conclusion}

In conclusion, we are definitely able to strengthen evidence that her $2 /$ neu positive patients do profit from continued trastuzumab therapy, with a clinical benefit rate of $68.5 \%$ in the second line. We are to our best knowledge the first group reporting a similar TTP in $1^{\text {st }}$ line, $2^{\text {nd }}$ line and beyond $2^{\text {nd }}$ line treatment, making our data especially noteworthy. Further, this is among the first studies reporting a beneficial role of trastuzumab combination even beyond second line. Albeit the here presented data, randomised trials are still warranted to make a final conclusion regarding treatment continuation possible.

\section{Declaration of competing interests}

The author(s) declare that they have no competing interests.

\section{Authors' contributions}

$\mathrm{RB}$ contributed the idea for this trial, participated in the design and drafted the manuscript, CW participated in the statistical analysis and helped drafting the manuscript, DH participated in the design of the study, UP and US both participated in the collection of patient data, WK helped in the design and coordination of the study, GA recorded patient data, GL revised the manuscript critically, RM assisted in the statistical analysis, CZ and GS were important in the design of the study, the coordination and helped to draft the manuscript.

All authors have read and approved the final manuscript.

\section{References}

I. Boyle P, Ferlay J: Cancer incidence and mortality in Europe 2004. Ann Oncol 2005, 2:68-75.

2. Hill C, Doyon F: The frequency of cancer in France in the year 2000, and trends since 1950. Bull Cancer 2005, 92:7-II.

3. Mollick JA, Carlson RW: Rational surveillance programs for early stage breast cancer patients after primary treatment. Breast Dis 2004, 2 I:47-54.

4. Cianfranco M, Goldstein LJ: Prognostic and predictive factors in early-stage breast cancer. Oncologist 2004, 9:606-16.

5. Subramaniam DS, Isaacs C: Utilizing prognostic and predicative markers in breast cancer. Curr Treat Options Oncol 2005, 6:147-59.

6. Ligibel JA, Winer EP: Trastuzumab/chemotherapy combinations in metastatic breast cancer. Semin Oncol 2002, 29:38-43.

7. Thomssen C: Trials of new combinations of Herceptin in metastatic breast cancer. Anticancer Drugs 200I, I 2(Suppl 4): |9-25.

8. Vogel $C L$, Franco SX: Clinical experience with trastuzumab (herceptin). Breast J 2003, 9:452-62.

9. Burstein HJ, Harris LN, Marcom PK, Lambert-Falls R, Havlin K, Overmoyer B, Friedlander RJ Jr, Gargiulo J, Strenger R, Vogel CL, Ryan PD, Ellis MJ, Nunes RA, Bunnell CA, Campos SM, Hallor M, Gelman R, Winer EP: Trastuzumab and Vinorelbine as first-line therapy for Her2-overexpressing metastatic breast cancer: multicenter phase II trial with clinical outcomes, analysis of serum tumor markers as predictive factors, and cardiac surveillance algorithm. J Clin Oncol 2003, 21 :2889-95.

10. Winer EP, Burstein HJ: New combinations with herceptin in metastatic breast cancer. Oncology 200 I, 6 I (Suppl 2):50-7.

II. Yarden Y, Baselga J, Miles D: Molecular approach to breast cancer treatment. Semin Oncol 2004, 31:6-13.

12. Esteva FJ: Monoclonal antibodies, small molecules, and vaccines in the treatment of breast cancer. Oncologist 2004, 9(Suppl 3):4-9.

13. Bianco AR: Targeting c-erbB2 and other receptors of the cerbB family: rationale and clinical applications. J Chemother 2004, I 6(Suppl 4):52-4.

14. Jahanzeb M, Mortimer JE, Yunus F, Irwin DH, Speyer J, Koletsky AJ, Klein P, Sabir T, Kronish L: Phase II trial of weekly Vinorelbine and Trastuzumab as first-line therapy in patients with Her2(+) metastatic breast cancer. Oncologist 2002, 7:4I 0-7.

15. Montemurro F, Valabrega G, Aglietta M: Trastuzumab-based combination therapy for breast-cancer. Expert Opin Pharmacother 2004, 5:81-96. 
16. Jahanzeb M: Trastuzumab-Based Combinations in Metastatic Breast Cancer: How to Make a Choice. Clinical Breast Cancer 2003, I:28-38.

17. Suzuki Y, Tokuda Y, Saito Y, Ohta M, Tajima T: Combination of trastuzumab and vinorelbine in metastatic breast cancer. Jpn J Clin Oncol 2003, 33:5 I4-7.

18. Burstein HJ, Kuter I, Campos SM, Gelman RS, Tribou L, Parker LM, Manola J, Younger J, Matulonis U, Bunnell CA, Partridge AH, Richardson PG, Clarke K, Shulman LN, Winer EP: Clinical activity of trastuzumab and vinorelbine in women with Her2 overexpressing breast cancer. J Clin Oncol 2004, 15:2722-30.

19. Marty M, Cognetti F, Maraninchi D, Snyder R, Mauriac L, TibuanaHulin M, Chan S, Grimes D, Anton A, Lluch A, Kennedy J, O'Byrne K, Conte P, Green M, Ward C, Mayne K, Extra JM: Efficacy and Safety of Trastuzumab Combined With Docetaxel in Patients With Human Epidermal Growth Factor Receptor 2-Positive Metastatic Breast Cancer Administered as First-Line Treatment: Results of a Randomized Phase II Trial by the M7700 I Study group. J Clin Oncol 2005, 23:4265-74.

20. Leyland-Jones B, Gelmon K, Ayoub JP, Arnold A, Verma S, Dias R, Ghahramani P: Pharmacokinetics, safety, and efficacy of trastuzumab administered every three weeks in combination with paclitaxel. I Clin Oncol 2003, 2 I:3965-7I.

21. Kaplan EL, Meier P: Non parametric estimation for incomplete observations. J Am Stat Ass 1958, 53:457-48I.

22. Fountzilas G, Razis E, Tsavdaridis D, Karina M, Labropoulos S, Christodoulou C, Mavroudis D, Gogas H, Georgoulias V, Skarlos D: Continuation of trastuzumab beyond disease progression is feasible and safe in patients with metastatic breast cancer: a retrospective analysis of 80 cases by the Hellenic cooperative oncology group. Clin Breast Cancer 2003, 4:120-5.

23. Tripathy D, Slamon DJ, Cobleigh M, Arnold A, Saleh M, Mortimer JE, Murphy M, Stewart SJ: Safety of treatment of metastatic breast cancer with trastuzumab beyond disease progression. J Clin Oncol 2004, 22: 1063-70.

24. Gelmon KA, Mackey J, Verma S, Gertler SZ, Bangemann N, Kilmo P, Schneeweiss A, Bremer K, Soulieres D, Tonkin K, Bell R, Heinrich B, Grenier D, Dias R: Use of trastuzumab beyond disease progression: observations from a retrospective review of case histories. Clin Breast Cancer 2004, 5:52-8.

25. Osoba D: Health-related quality of life as a treatment endpoint in metastatic breast cancer. Can J Oncol 1995, 5(Suppl I):47-53

26. Payne SA: A study of quality of life in cancer patients receiving palliative chemotherapy. Soc Sci Med I992, 35: I505-9.

27. Eiermann W: trastuzumab combined with chemotherapy for the treatment of HER"-positive metastatic breast cancer: pivotal trial data. Ann Oncol 200I, I 2(Suppl I):57-62.

28. Ritter CA, Bianco R, Dugger T, Forbes J, Qu S, Rinehart C, King W, Arteaga CL: Mechanisms of resistance development against trastuzumab (Herceptin) in an in vivo breast cancer model. Int J Pharmacol Ther 2004, 42:642-3.

29. Vidal L, Attard G, Kaye S, De Bono J: Reversing resistance to targeted therapy. J Chemother 2004, I6(SuppI 4):7-12.

\section{Pre-publication history}

The pre-publication history for this paper can be accessed here:

http://www.biomedcentral.com/1471-2407/6/63/prepub
Publish with Biomed Central and every scientist can read your work free of charge

"BioMed Central will be the most significant development for disseminating the results of biomedical research in our lifetime. "

Sir Paul Nurse, Cancer Research UK

Your research papers will be:

- available free of charge to the entire biomedical community

- peer reviewed and published immediately upon acceptance

- cited in PubMed and archived on PubMed Central

- yours - you keep the copyright

Submit your manuscript here:

http://www.biomedcentral.com/info/publishing_adv.asp
BioMedcentral 